\title{
Estudio comparativo de la carta de población de Tortosa (1149), carta de población de Lleida (1150) y la carta de franquicia de Mallorca (1230)
}

\author{
Eduardo Pascual Ramos
}

\begin{abstract}
RESUMEN
El objetivo principal de este artículo es un análisis diplomático comparativo de

la Carta de población de Tortosa (1149), de la influencia que ejercerá en la Carta de población de Lleida (1150) y posteriormente en la Carta de franquicia de Mallorca (1230) Dentro del conjunto de Cartas de población de mediados del siglo xil la Carta puebla de Tortosa supuso la avanzadilla del derecho local, con un estilo sencillo $y$ un cuidado especial en conceptos $y$

formulaciones, no corrientes en la época, que suministró el modelo de ordenación en Lleida y Mallorca. Tomando como referencia la Carta de Tortosa se pasa analizar los capítulos que manifiestan influencia que en el caso de la Carta de población de Lleida es esencialmente calcada e influyendo en la Carta de franquicia de Mallorca en diez de los treinta y siete capítulos.
\end{abstract}

\section{ABSTRACT}

The main aim of this article is a diplomatic comparative analysis of the tortosa civil rights bill, its influence upon then Lleida civil rights bill and, later, upon the Majorcan exemption rights bill. Looking at the civil rights bill of the middle of the xith century as a whole, the Tortosa civil rights bill meant a step forward in local law, with its simple style ant its special care as far as concepts and formulations, umsual at that time, which provided the model of future regulations in Lleida and Majorca. Taking as reference the Tortosa bill, the chapters that demonstrate its influence can be analysed. In the case of Lleida civil rights bill is a complete copy and it has a marked influence on ten of the thirtyseven chapters of the Majorcan exemption rights bill. 
Las cartas de población y franquicias deben entenderse como «privilegio» en el marco jurídico medieval. El privilegio responde a la idea de una concesión particular del soberano o señor jurisdiccional a favor de un ente personal o colectivo, caracterizado por distintos principios. Dentro de tal heterogeneidad, debemos aproximarnos al tipo de privilegio dirigido a un núcleo de población, destinado a fomentar la población de un lugar o la permanencia de su núcleo morador mediante la fijación de unas condiciones básicas de tenencia de su suelo, de habitación del mismo, y el establecimiento de normas elementales para encauzar la vida jurídica de la vida comunal. Según consideraciones del profesor Font i Rius ${ }^{1}$ se pueden establecer varios grupos de modalidades y tipos de cartas de franquicias y de población que pueden dividirse en varios apartados:

a) Donaciones o licencias «ad populandum». Concesiones individuales o familiares para repoblación en donación. Éstas eran pre-Cartas que se utilizaron, sobre todo, en los avances cristianos en Cataluña Nueva (siglos XI-XII).

b) Establecimiento agrario colectivo. Esta vendría a ser la carta de puebla, que se concedía para el cultivo a favor de un grupo de hombres por parte de su señor dominical. La concesión de dicho tipo de carta no sólo hace referencia al suelo cultivable sino a los bienes de uso común como podrían ser las aguas, prados, bosques...

c) Establecimientos aldeanos vecinales. Se da con idea de establecimiento de una comunidad vecinal de construcción, villa o poblado. Es de interés fundamental para asegurar un núcleo de habitantes con cierto cariz urbano.

d) Cartas de franquicias y privilegios. Estas eran concesiones colectivas que se otorgaban a los pueblos. No se les concedían tierras, sino un complejo de privilegios o seguridades. Las franquicias son ofrecidas a los pobladores de un lugar, ya sea para atraer a un contingente morador, al igual que indirectamente, operaba en sentido de evitar el riego de una «despoblación».

e) Estatutos primarios de la vida jurídica local. En este apartado, se da una recapitulación de los elementos presentes en las categorías anteriores. Se dan disposiciones propias de un establecimiento agrario o aldeano, además, un complejo normativo hacia la regulación para la convivencia de una colectividad vecinal. El prototipo de esta categoría lo presenta la de Tortosa-Lleida de redacción paralela.

FONT I RIJS, J.M. Cartas de población y franquicias de Cataluña. Vol I, Il y apéndice. Consejo Superior de investigaciones Científicas. Madrid, 1969. 
La Carta de Población de Tortosa, de 1149, fue objeto de una preparación más técnica que las anteriores, ya que ésta, se confeccionó con un claro deseo de atracción para la repoblación en el final de la reconquista de Cataluña Nueva. Si tenemos presente además, el intervalo de cerca de un año que medió entre la conquista de la plaza por el ejército cristiano y el otorgamiento de su carta puebla, podría pensarse que hubo una tramitación interna de estudio y confección de su texto por los círculos allegados a la persona del conde de Barcelona. Por contraste advertimos, que para la concesión de la similar Carta de Lleida sólo mediaron unos pocos meses (de octubre de 1149 a enero de 1150), entre la conquista de la plaza y concesión de la Carta, comprensible porque disponiendo ya del patrón tortosiano, no había más que aplicarlo a Lleida, con la introducción de unas variantes relativas a la especialidad local. La Carta de Franquicia de Mallorca se inscribe dentro de una larga lista de actas parecidas desde 1148 a 1213, estipulándose que serán otorgadas 130 Cartas de población por los condes de Barcelona con el objeto de estimular la repoblación de los nuevos pobladores. La Carta de Franquicia de Mallorca no es un documento atípico, ya que se denota una gran influencia con la Carta de Tortosa y de Lleida, aunque dispone de un gran numero de disposiciones progresistas para su época.

\section{CARTA DE POBLACIÓN DE TORTOSA (1149)}

Ocupada la ciudad en los últimos días de 1148 por las tropas del conde Ramón Berenguer IV, con unas capitulaciones concertadas con los musulmanes de la plaza, se confeccionó una carta puebla dada en su nombre y con la asesoría de Guillermo Ramón de Moncada a los moradores presentes y futuros de la villa de Tortosa. En ella le hace donación de la villa con sus términos y pertenencias, les exime de impuestos de tránsito y se esbozaban las líneas generales de las normas jurídicas de la urbe, en donde se despliega un conjunto de normas de derecho privado, penal y procesal para la administración de justicia.

\section{Estructura interna}

El inicio diplomático de la Carta de Tortosa comienza por una invocacion solemne a la Trinidad en sus personas: 
El protocolo prosigue con la titulación del otorgante, con una fórmula de humildad (gratia Dei) y con sus respectivos títulos:

Ego Raimundus Berengarii, comes gratia Dei Barchilonensis, princeps Aragonensis, atque llerde et Tortose marchio

El cuerpo del documento comienza con la notificación de donación (dono), de forma libre y voluntaria, de las propiedades y posesiones tanto bienes públicos como privados a los nuevos pobladores de Tortosa, tanto a los presentes como a los sucesores (omnibus habitatoribus Tortose cunctisque successoribus vestris in perpetuum in civitate Tortosa) en herencia libre, franca e ingenua. Las propiedades públicas que se donan son los bosques, montes, prados, pastos, cacerías así como la madera que se podrá utilizar para uso doméstico al igual que las aguas dulces y mar para pescar y navegar. Las propiedades privadas, que se concederán con las donaciones particulares, serán las casas, caseríos, huertas, campos, viñas, cultivados o yermos:

domos et casales, ortos et ortales, campos et vineas cultos et heremos cum omnibus earum pertinentiis in hereditate propria libera franca et ingenua sicut unicuique dabo per donationes meas et Cartas quas facturus sum vobis. Dono etiam vobis montes et planos et boschos et ligneamina ad omnes vestros usus propios tam domorum quam navium. Dono etiam vobis prata et paschuas et venationes. Et habeatis hec omnia vos et omnes successores vestri post vos libere et ingenue cum ómnibus ingressibus et egressibus sicut habentur et continentur. Dono iterum vobis ómnibus aquas dulces et mare ad piscandum et navigandum

Una excepción a la donación será la que el conde de Barcelona se reserve la novena parte de los estanques y salinas, hecho de enorme calado en la Carta de Franquicia de Mallorca en donde el soberano lo tomará de referencia:

exceptis stagnis et salinis in quibus retineo solam meam novenam.

Pasando a delimitar los términos de la territorialidad:

terram de collo Balagerii unque ad Ulldichona et sicut pervadit de rocha Foletera usque ad mare.

Continúa el dispositivo con unas breves cláusulas de franquicias con la exención de determinados impuestos como lauda, portatico, passatico y la garantía a no ejercer contra ellos por parte de la autoridad o sus agentes, fuerza ni violencia alguna y proceder según ordena justicia: 
Dono insuper ómnibus vobis quod non donetis amodo in Tortosa leudam neque portaticum neque passaticum. Et quod non faciam vobis nec successoribus vestris aliquam fortiam vel districtum in personis vestris vel in possessionibus mobilibus aut inmobilibus neque per me neque personas mihi subditas nisi quod sola iustitia mihi dictaverit, quam iustitiam tenebitis et observabitis secundum mores bonos et consuetudines quas subterius vobis dedi et scribi feci.

La parte central del cuerpo textual de las cartas de población y franquicia es la regulación jurídica que establece la situación básica de la administración de justicia en el ámbito vecinal. En donde se articulan medidas para salvaguardar la convivencia social entre cristianos, judíos y sarracenos y afirmando el mantenimiento del orden público.

Con la frase "secundum mores bonos et consuetudines quas subterius vobis dedi et scribi fecis se permite conjeturar sobre la posible existencia de una recensión estatutaria autónoma, pero acoplada a la Carta. Se da paso directo a la exposición de tales normas con la frase:

Primus siquidem modus Tortose civitatis hic est.

En la cual se normalizan diversos tipos de casos comunes en su época:

El delito de deuda queda bien patente en las tres cartas. En la Carta de Población de Tortosa la justicia sólo actuará contra el deudor o deudores, si el acreedor no recupera la deuda en caso en supuesto de ausencia o de insolvencia del principal obligado. El acreedor llevará el caso a la Curia para que ésta haga justicia. El deudor tendrá que pagar íntegramente la deuda más una quinta parte de lo que costase la deuda a la Curia de Tortosa, en gastos de minuta:

Quicumque alicui extiterit debitor et ad terminum noluerit eum paccare postquam exactor querimoniam suam super hoc curie exposuerit, causam suam debitor integre ei restituat et postmodum quantum constaverit quinta pars illius debiti quod reddiderit tantum de propio suo idem debitor curie reddat.

Si algún encolerizado amenazare a una segunda persona con espada, cuchillo o lanza tendrá que pagar sesenta sueldos a la Curia o (aut) la amputación de la mano derecha. Dicha medida vendrá mejor desarrollada en la Carta de Lleida y de Mallorca:

Si quis etiam minando aut irascendo contra alium, cultellum vel ensem vel lanceam traxerit, $L X$ solidos curie donet aut manum dexteram perdat. 
El que sorprenda in fraganti a un ladrón, podrá retenerlo hasta recobrar la cosa robada y lo confiará luego a la justicia para que lo penalice según corresponda:

Qui autem prendiderit latronem in latrocinio teneant eum donec sua recuperet et postea illum ad iustitiam curie reddat.

En cuanto a la regulación de la prenda judicial establece el documento que la deuda será devuelto en un plazo fijo, la cual si no fuese devuelto en su plazo se guardará por el espacio de $\operatorname{diez}(X)$ días más, y si no se recupera lo adeudado se podrá vender o empeñar para recuperar el dinero. $Y$ si el deudor fuese un soldado, ampliándose el campo de los deudores, faculta al acreedor, en caso de no haber devuelto lo que le debe en el plazo establecido, a embargarle, delante de la Curia, su caballo o mulo y el cual no le podrá discutir la acción:

Pignera vero debitorum coram testibus accipiantur ad terminum; que si tunc non fuerint redempta conserventur inde post terminum $X$ dies; que si tunc redempta non fuerint sit deinceps licitum eis qui tenuerint eam vendere vel impignorare sine alicuius contrarietatis obstáculo. Et si quis miles alicui homini vel femine Tortose fuerit dator vel debitor per se vel per alium et statuto termino noluerit reddere quod debuerit postquam exactor semel fuerit de eo fatigatus ad curiam, pigneret deinde suum datorem vel debitorem de cavallo suo aut de mulo aut de quibuslibet rebus suis quas cum eo vel sine eo invenire potuerit.

En caso de llamar calabaza(adultero), renegado o bausudotraidor,( cuguz, renegatum aut bandatorem) se le exime de toda responsabilidad penal si tomándose la justicia por su mano, lo agrediere. Curiosamente no se articula norma en caso de adulterio:

Et ipse dator vel debitor pignus ei non deffendat neque contendat. Et si quis apellaverit alterum cucurbitam, hoc est cuguz aut renegatum aut bandatorem et aendem ora percusserit eum, ille cui hoc verbum protulerit nulla de eis vindicta vel iustitia requiratur.

Se podrá pedir la participación judicial en caso de controversias o injurias para una conciliación de las partes ante los prohombres de la ciudad facultados para pacificar y definir litigios antes que se formularan la demanda ante la Curia:

Contentiones vel alia malefacta que fuerint infra habitatores Tortose sit iicitum probis hominibus aptare et pacificare ad invicem si voluerint antequam curiam manifestentur vel ad juramentum deveniant. 
Estudio comparativo de la carta de población de Tortosa (1149), carta de...

En caso de reiterada desavenencia se procederá a dar conocimiento a la Curia iniciándose el litigio y haciendo justicia por los prohombres de la Curia. Se manifiesta un claro papel activo de los prohombres para las posibles conciliaciones previas:

De iniuriis et malefactis que facte fuerit postquam clamor fuerrit factus ad curiam, firment inde directum et faciant per iudicium curie et proborum hominum Tortose.

Continua con un artículo en referencia al pago de un o dos maravedíes por la captura de sarracenos fugitivos dentro de los límites de Tortosa. Dicha medida tiene un carácter local y no tendrá continuidad ni en la Carta de Lleida ni en la de Mallorca.

Pro inventione vero fugitivi sarraceni qui inventus sit de Terrachona usque Iberum flumen unum morabetinum accipiatur. Et de Ibero usque ad Uldichona duos.

A continuación se redacta el contrato vasallático por el cual las dos partes aludidas pasan a garantizar tanto las donaciones como el cumplimiento de la acción jurídica arriba expuestas La primera parte del contrato vuelve a recordar que el conde dona las propiedades de forma franca y libre. $Y$ que actuará como buen señor defendiendo a sus vasallos y sus pertenencias y en caso de queja no batalléis contra el conde o alcalde de Tortosa:

Supradicta omnia vobis dono francamente et libera et sine vestro enganno modo prescripto ut ea potenter et firmiter teneatis et habeatis ac iure perpetuo possideatis salva in ómnibus mea fidelitate et meis directis, et amodo ero vobis bonus rector et bonus dominus et amabo semper atque honorabo et defensabo personas vestras et omnia vestra ubicumque per me vel per meos posse habuero sicut meos proprios et michi karissimos. Addo iterum vobis quod per clamorem aut per ullum reptir quod vobis facerem non faciatis mecum batiam neque cum ullo seniore aut baiulo de Tortosa...

La segunda parte contratante da por entendido lo arriba escrito por parte de los habitantes de Tortosa y convienen e serles fieles:

Propter hec omnia dona superius comprehensa, nos omnes habitatores Tortose convenimus vobis domino nostro Raimundo comiti suprascripto ut simus vobis fideles in omnibus.

El escatocolo comienza con la fecha de la redacción de la carta, en donde se especifica día, con sistema romano, mes y año por el estilo del año de la Encarnación: 
Facta ista Carta II Kalendas decembris, die festo sancti Andree, anno. Dominice Incarnationis millesimo centesimo quadragesimo nono.

Así como los firmantes que valida la Carta. El primer signante de la lista corresponde al conde de Barcelona continuando con la clase eclesiástica y la clase nobiliaria:

Sig+num Raimundi, comes.

Sig+num Bernardi, Terrachonensis archiepiscopi. Sig+num Guillermi, Barchinonensis episcopi. (Signo). Sig+num Guielmi Raimundi Dapiferi. Sig+num Petri Bertrandi. Sig+num Petri Sanctiminati. Sig+num Bernardi de Belloloco. Sig+num Pontii de Cervera. Sig+num Guillelmi de Copons, baiuli comitis.

Termina el protocolo final con la autentificación de la carta con la firma del escribano que realizó el documento(Pontii), el cual será el mismo que redactará la Carta de Lleida, y recordando la data anteriormente indicada:

Sig+num Pontii qui hoc scripsit die annoque prescripto.

\section{CARTA DE POBLACIÓN DE LLEIDA (1150)}

La reconquista cristiana de Lleida se realiza a finales de octubre de 1149, por las tropas del conde barcelonés Ramón Berenguer IV y del conde de Urgell Ermengol VI. La actuación decisiva de los elementos barcelonés y urgelenses en la conquista de Lleida, se reflejó en el doble señorío de las casas de Barcelona y de Urgell sobre la ciudad y su término. Les conceden la plena propiedad de sus casas y tierras de labores, para que las edifiquen y habiten, y el libre aprovechamiento de pastos y bosques. Les eximen de lezda y usatico y ordenan la administración de justicia ${ }^{2}$.

\section{Estructura interna}

La Carta puebla comienza diplomáticamente con una notificación autocalificativa de modo que sean todos aludidos:

Sit notum omnibus.

2 La Carta de Población de Lleida pasó a encabezar el título I del Libro I de las Consuetudines llerdenses Redactada en 1228 por el jurista Guillermo Botet. Las Consuetudines recoge los privilegios recibidos de los soberanos así como costumbres y estatutos escritos y costumbres no escritas. 
Con la partícula copulativa "quod» enlaza con el protocolo de la carta. El pronombre «ego" inicia la titulación de los otorgantes de la Carta con sus nombres y títulos. El conde de Barcelona se encuentra en primera instancia como soberano, aquí ya no se califica príncipe de Lleida y marqués de Tortosa sino marqués de Lleida y Tortosa. Continua la titulación con, el co-otorgante conde Armengol, al cual por donación de Ramón Berenguer le dona Lleida tras una previa relación feudal que condiciona la concesión de la carta estableciéndose el otorgamiento conjunto:

Sit notum omnibus hominibus quod ego Raimundus, comes Barchinonensis princeps Aragonensis atque llerde et Tortose marchio, et ego Ermengaudus, comes Urgellli qui per manum comitis Barchinonensis llerdam habeo,

Continúa anunciando el asunto que es objeto el documento, es decir, con la notificación, que entra con un verbo en imperativo en segunda persona del plural, «donamus» el cual inicia la concesión a todos los habitantes de Lleida tanto presentes como a los que han de venir:

donamus vobis omnibus populatoribus et habitatoribus sive statoribus llerde civitatis tam presentibus quam futuris,

A continuación se pasa a desglosar todas las donaciones de realengo a los habitantes y con una concesión explícita que se limita a casas, casales(construidas como destruidas, intra como extramuros), huertos y hortales al igual que todo el territorio de Lleida, como los prados, arboledas, caza, llanos y montes así se elimina la larga lista de donaciones que contenía la Carta de Tortosa. Con la donación se da derecho a la construcción y habitabilidad de las casas, primer objetivo de las cartas de repoblación:

casas et casales, et ortos et ortales, et totam civitatem llerde tam constructam quam distructam, tam infra muros quam extra muros, ut ibi habitetis et populetis et mansiones edificetis. Etiam damus vobis totum territorium civitatis llerde, tam cultum quam eremum, cum omnibus terminis et pertinentiis, omnesque introitus et exitus suos, ut habeatis ibi mansiones et hereditates vestras

Las donaciones generales se limitan cuando se determinan las donaciones individuales con una cláusula para la donación particular que serán dadas a los habitantes que así lo soliciten, pudiendo, una vez dada la concesión, venderla o empeñarlas. Al igual que Tortosa existe la cláusula de prohibición de donación del patrimonio privado a soldados e Iglesia: 
sicut unicuique vestrum eas dabimus per Cartas nostre donationis, per alodium propii, et franchum, cum prole et sine ea, ad faciendum ex inde quidquid voluerities tamquam de propiis hereditatibus vestris, ad dandum vel vendendum sive impignegrandum quibuscumque velitis, exceptis militibus et sanctis.

La cláusula a la prohibición de venta de las clases aludidas tiene un carácter innovador ya que se intenta limitar la expansión de la clase militar y religiosa. Esta cláusula tendrá un reflejo en el artículo dos de la Carta de Franquicia de Mallorca, que será sustancialmente calcada.

El cuerpo dispositivo continua con un apartado que les exime determinados impuesto como lezda y «usatico». Estas exenciones económicas, con las donaciones particulares, contendrán los principales motivos de atracción de los nuevos pobladores:

Donamus iterum vobis omnius ut deincebs in civitate llerde et in termino eius non donetis leudam nec ullum usaticum.

La exención enlaza con una mención a la protección de los derechos individuales en el tema de la imposibilidad que ni baile, castellano, ni lugarteniente, ni señor puedan diputarse ni detener en las propiedades otorgadas y que solamente sea a través de la norma de justicia que a continuación se dicta:

Et quod nos aut aliquis senior vel castlanus sive vicarius aut baiulus llerde homo vel femina non faciamus vel faciant ullam forciam vel districtum in personis vestris neque in possessionibus vestrisquod nos aut ullus senior vel llerde non possimus vel possint vos inculpare aut increpare de aliquo absque legitimis et idoneis testibus; et quod non faciatis nobiscum aut cum aliquo seniore vel baiulo llerde bataiam baiulus.

Recordando la garantía de los derechos individuales dados a los habitantes de Lleida siendo, igual que en Tortosa, libres y francos (securi, liberi et franchi) tanto de sus personas como de sus bienes y de no ejercer contra ellos por parte de la autoridad o sus agentes, fuerza ni violencia alguna y proceder más que en la recta justicia:

Et quod sitis deincebs securi, liberi et franchi cum omnibus hereditatibus vestris atque possessionibus vestris absque aliquo retentu quem ibi non facimus, preter fidelitatem et solam rectam iustitiam quam ibi reinemus, quam iustitiam et fidelitatem ita tenbitis et observabitis, sicut inferius scriptum est et constitutum.

Estas gararitías de derechos individuales nos recuerda que no existían derechos preexistentes y los nuevos derechos de libertad emanaban de la 
Estudio comparativo de la carta de población de Tortosa (1149), carta de...

voluntad del soberano. Estos campos de libertad contendrán los incentivos para la atracción de los nuevos colectivos además de la garantía para que no puedan ejercer abusos por parte de las autoridades.

Tras la recensión estatutaria continua con la exposición de las normas de justicia con la siguiente frase:

Primus, siqudem, modus institutionis et observationis iustitie hic est.

Las siguientes prescripciones de índole jurídico privada y especialmente penal y procesal no presentan un carácter local ligado al fenómeno repoblador, pero si establece el marco jurídico para la convivencia con una garantía de orden público y policial.

Los delitos de amenaza con cuchillo espada o lanza (cultellum, ensem aut lanceam) se tendrán que pagar una multa de sesenta sueldos (XL solidos) o la pérdida de una mano, no especificándose cual. Existe una pequeña variante de la pena con respecto a la Carta de Tortosa ya que en ésta se especificaba la mano derecha. El artículo contiene medidas para solucionar un problema, tal vez, común para su tiempo. Intentando que se lo pensaran antes de realizar dicha acción ante la gran suma de dinero:

Si quis eduxerit cultellum aut ensem aut lanceam adversus alterum, minando vel irascendo, aut donet curie XI. solidos aut manum perdat.

El robo, como violación de los derechos de propiedad, es exactamente igual al de Tortosa El cual describe que en caso de encontrar ladrón robando sus bienes, in fraganti, lo retendrá hasta haber recuperado lo robado para posteriormente entregarlo a la Curia:

Qui autem prendiderit latron€m suas casas ei furantem, tandiu eum teneat donec sua recuperet, et post modum illum ad iustitiam curie reddat.

La regulación en caso de deuda tiene un claro cuño tortosiano. La norma regula en caso de negarse a pagar la deuda al vencimiento del plazo, se podrá retener la prenda por espacio de diez días y será permitido venderla o empeñarla para recuperar la suma en caso de vencimiento de la segunda prorroga. También la minuta de la Curia aumenta de una quinta parte se pasa a una tercera parte del coste de la deuda. En caso que la Curia no quisiera o no pudiera obligar al deudor a pagar la deuda, será lícito que el demandante directamente pueda confiscarles caballos, mulas o cualquier tipo de bienes (cavallo aut mulo aut de quibuslibet rebus) para recuperar lo adeudado: 
Et si quis tenuerit pignus alterius, et ipse qui debitor fuerit noluerit debitum ad terminum redere, teneat ipsum pignus qui tenet decem diebus post illum terminum, post quos si noluerit debitor reddere debifum, ex tunc sit licitum ei qui pingnus tenuerit, vendere vel impignorare illud cui voluerit unde suum recuperet. Si quis vero fuerit debitor aut fideiussor alicui habitatori vel statori llerde et ad terminum noluerit eum pachare, si clamor de eo venerit ad curiam, cogatur debitor ille vel fideiussor totum ei reddere debitum, et tantum curie de suo propio dare, quantum fuerit tertia pars illius debiti. Quod si curia nollet aut non posset ipsum debitorem vel fideiussorem distringere, ex tunc sit licitum habitatori llerde pignerandi debitorem ipsum vel fideiussorem in cavallis aut mulis aut in omnibus propiis rebus ipsius quascumque invenerit.

Los litigios ya sean injurias y detrimentos se podrán solucionar a través de prohombres (probi homines) antes que lleguen a la Curia, si ambas partes estuvieran de acuerdo. En caso de no llegar acuerdo se tendrá que realizar en los tribunales de la Curia, y se procederá a un juicio directo según la cantidad del daño. Existe un claro deseo de los órganos de justicia a la reconciliación de ambas partes con el asesoramiento de los prohombres de la ciudad. Este artículo es exacto al de Tortosa, lo que lo diferencia son las denominaciones de agravios:

Omnes vero in iniurias et omnia malefacta que fuerunt infra habitatores llerde, habeant licentiam probi homines llerde ea ad invicem adaptare et pacificare si voluerint, antequam ad curiam querimonia inde feratur. De illis autem iniuriis et malefactis de quibus fuerit clamor curie factus, firment inde directum secundum quantitatem malefacti, et faciant illud per iudicium curie.

En la Carta de población de Lleida el adulterio es un delito público y por lo tanto se amplía y se endurece la pena por adulterio. En caso de ser cogidos los adúlteros serán obligados ambos a ser paseados desnudos y azotados por las calles de la ciudad, si dejar por esto de pagar el daño de honor y los intereses. La Carta de población de Tortosa se contempla en caso de llamar adúltero pero no llegando a articular medidas en caso de adulterio. La Carta de Mallorca se contempla el adulterio desde una mayor permisividad:

Et si quis fuerit captus in adulterio cum uxore alterius, currant ambo vir et mefina per omnes plateas civitatis llerde, nudi et verberati, nec aliud dapnum honoris vel pecunie inde sustineant.

Esta última parte del cuerpo del documento se centra en el contrato mutuo de ambas partes al acuerdo de fidelidad y cerrándose con una 
cláusula de obligatoriedad. La primera parte hace mención a la promesa de los donantes, el conde de Barcelona y de Urgell, de atenderlos, defenderlos, tanto por mar como por tierra, a todos los habitantes. Aquí no se hace mención al caso de mal entendimiento que se podría llegar al enfrentamiento entre las autoridades y el pueblo sino que se omite al entenderse que se regularizará a través de la justicia:

Et nos prescripti comites Barchinonensis scilicet et Urgellensis, convenimus vobis omnibus habitatoribus Ilerde omnia suprascripta tenere firmiter et atendere bona fide sine vestro engan, et manutenebimus et defensabimus corpora vestra, et omnia vestra in omnibus locis maris et terre ubi potentiam habeamus contra omnes homines et geminas sicut nostros propis atque karissimos homines.

En la segunda parte del contrato los habitantes de Lleida ratifican y se comprometen a la mutua fidelidad pasando de esta forma a ser súbditos y conservando la ciudad y villa según lo establecido en la donación:

Et nos omnes pariter populatores atque statores llerde civitatis, maiores et minores, convenimus vobis senioribus nostres, Raimundo comiti Barchinonensi et Ermengaudo comiti Urgelllensi, quod ab hac die in antea simus vobis fideles in omnibus directis, iustitiis vestris, bona fide et sine aliqua fraude nobis scientibus, et quod adiuvemus vos tenere et conservare civitatem et villam llerde, secundum posse nostrum.

El contrato concluye con una cláusula de obligatoriedad a reparar doblemente lo acordado en caso de violación (duplo omnia supradicta componat):

Et si quis hoc disrumpere vel violare temptaverit nichil proficiat, sed in duplo omnia supradicta componat, et postmodum hoc firmum permaneat omne per evum.

El escatocolo comienza con la data completa de la realización, especificando, el día en calendas, el mes y el año por la costumbre de la Encarnación del Señor:

Facta ista Carta mense ianuarii, anno Domicice Incarnationis millessimo centessimo XL.VIIII.

A continuación empieza la validación de la carta encabezada, al igual que en la Carta de Tortosa, con la firma de Ramón Berenguer IV: 
Prosigue la Carta con la firma del conde de Urgell dejando constancia que la mandó realizar, así como hizo firmarla a los testigos:

Sig+num Ermengaudi, comitis Urgellit, qui hanc donationem fecit, firmavit testesque firmare mandavit.

Viene a continuación la larga lista de firmantes que dejan su impronta con sus nombres y apellidos:

Sig+num Arnalli Mironis, comitis Pallaresis. Sig+unm Guillelmi Raimundi Dapiferi. Sig+num Raimundi de Pugalt. Sig+num Arnalli de Belloloco. Sig+num Geralli de lorba. Sig+num Gillelmi de Cervera. Sig+num Guillelmi de Castelvel. Sig+num Arnalli Berengarii de Anglesola. Sig+num Gomballi de Ribeles. Sig+num Arnalli de Ponts. Sig+num Berengarii de Torroia. Sig+num Arnalli de Lercio.

Termina con la signatura del escribano(Pontii), que da validación a la Carta con la data arriba mencionada. El escribano fue el mismo que realizó la Carta de Tortosa, de ahí la gran similitud:

Sig+num Pontii, scriptoris qui hoc scripsit die annoque prescripto.

\section{CARTA DE FRANQUICIA DE MALLORCA (1230)}

Dos meses después de la toma de la ciudad de Mallorca, 1 de marzo de 1230 , el rey Jaime I concedió la Carta de Franquicia ${ }^{3}$ a los habitantes de la ciudad y de la isla, pasando a ser la base jurídica institucional. La elaboración del documento fue realizada por Guillermo Escrivá, Guillermo Rabasa y Guillermo de Sala. Al elaborar la Carta de Franquicia se tuvo en cuenta la Carta de Población de Tortosa y de Lleida, de la cual denota influencia diez de los treinta y siete capítulos de la Carta de Franquicia $(1,2,6,7,9$, $17,26,28,30,35)$. No se conserva la carta original, pero el texto consta por unas copias que se realizaron al realizarse un traslado el siete de agosto de 1248 por el batle real de Mallorca Arnau Font a instancia de los cónsules de Mallorca ${ }^{4}$. Sólo se analizan los artículos que denotan influencia.

3 Copias de la Carta de Franquicia de Mallorca se encuentran en llibre de privilegis dels reis de Mallorca, Llibre de sant Pere, Llibre de Franqueses, todas ellos en el Archiu del Regne de Mallorca. También en el Archivo de la Corona de Aragón se encuentran copias compulsadas en Procesos, vol. 87, cuaderno 1, fol. 1.

4 Álvaro Santamaria, La Carta de Franquicia de Mallorca. Anuario de estudios medievales, ก. ${ }^{\circ} 17$, pp. 208, 1987. 
Estudio comparativo de la carta de población de Tortosa (1149), carta de...

\section{Estructura interna}

La Carta de Franquicia comienza con un escueto protocolo en invocación solemne a Jesucristo:

In Chisti nomine.

Y con el «Manifestum» pasa a recordar tanto a los presentes como a los futuros la donación de la Carta por parte de Jaime I. Resaltar que la donación de la Carta se concede en primera persona de plural, «nos», o «damus» y solo se especifica la persona del rey aragonés con toda su titulación nobiliaria:

Manifestum sit omnibus tam presentibus quam futuris quod nos Jacobus, Dei gratia rex Aragonum et regni Maiorice, comes Barchinonensis, et dominus Montspesulani

La partícula "cum» enlaza con la donación pública y el otorgamiento y aprobación a todos los pobladores de la isla de Mallorca para el aprovechamiento del realengo como prados, pastos y aguas terrestres como marítimas, llanos, montes y la libertad de la leña para cualquier tipo de uso, así como pescar sin tener que pagar gabelas. Reteniendo para sí las albuferas y salinas (stagnis). El conde de Barcelona en la Carta de Tortosa retenía solo la novena parte de las aguas estancadas y de las salinas. Vemos como a la hora de confeccionar la Carta de Mallorca se tuvo en cuenta dicha retención:

\footnotetext{
cum presenti publica escriptura perpetuo valitura, per nos et omnes heredes ac succesores nostros, damus, concedimus et laudamus vobis dilectis et fidelibus nostris universus singuilis populatoribus regni et civitatis Maiorice et habitasoribus predictan civitatem et totam insulam ut ibi habitetum et populetis, et damus vobis casas et casales, ortos et ortales, et terminum civitatis, prata, pascua, aquas dulces, maria et littus maris, venationes, pascheria, plana et montanas, herbas, ligna ad domos et naves, et ligna alia construenda, et adomnes alios vestros usus, et possitis piscari in mari bibere, tamen stagnis retentis nobis.
}

El artículo dos (2) de la Carta de Mallorca continua el expositivo estableciendo las titularidades privadas a través de las donaciones pactadas. Están serán libres y exentas (francas et liberas), y podrán ser donadas a terceros, todo ello dentro de las condiciones que se establecen en las normas jurídicas de las cartas de donación, con excepción de caballeros e Iglesia (exceptis mulitibus et sanctis) ya que estos tenían un tratamiento 
fiscal privilegiado ${ }^{5}$. La carta de Tortosa y de Lleida se contemplaba exactamente dicha cláusula de propiedad con la prohibición de donación a caballeros o religiosos:

Possesiones autem omnes quas in civitate vel regno Maiorice habebitis, habeatis francas et liberas, sicut eas habebitis per Cartas nostre donaionis, et possitis de eis facere cum prole et sine prole omnes vestras voluntates cuicumque volueritis, exceptis mulitibus et sanctis.

A continuación el aparato judicial regula los diferentes aspectos de la administración de justicia. El cuadro judicial contempla las normas más comunes, que en muchos aspectos mostrará un interés por un tipo de justicia más objetiva y más humana...

El artículo seis (6) da cuenta de los casos de amenaza a mano armada. Se impondrá una multa de 60 sueldos o la pérdida de la mano, a aquel que amenace a otro desvainando espada o cuchillo. Este tipo de medida se establece para la salvaguarda de la convivencia social. Ya en la Carta de Tortosa y Lleida vienen reflejadas esta situación, siendo exacta a la de Lléida:

Si quis traxerit cultellum vel ensem versus alium injuiando vel irascendo, donet nostre curie sexaginta solidos vel manum perdat.

El artículo siete (7) hace mención en caso que encontrara ladrón in fraganti en su casa lo podrá retener hasta que haya recuperado lo robado entregándolo posteriormente a la Curia. Este artículo esta basado exactamente en la Carta de Tortosa y posteriormente tomándose como referencia dicha Carta se redactaron sin modificación en Lleida y Mallorca:

Si quis fuerit captus in latrocinio aliquas res furando, teneat ille culus res fuerit latronem illum donec suas res recuperet: postea reddat illum curie ad justiciam faciedam.

El adulterio como delito privado vendrá estipulado de una forma permisiva. En este artículo declara que en caso de adulterio nadie será sancionado castigado en sus bienes ni en sus personas salvo si hubiere violencia. Pasando de delito público a delito privado y sancionable de oficio si las partes infamada pone demanda teniendo que probar el adulterio. Esto se ajusta a una nueva política de permisividad de la nueva sociedad maIlorquina. La Carta de Lleida contenía unas condenas a los adúlteros que iba desde correr desnudos a ser azotados por las calles de la ciudad. Por

\footnotetext{
5 Cateura Bennàsser, Pau. Malloca en el segle xil. Conèxer Mallorca. 1197, p. 27.
} 
Estudio comparativo de la carta de población de Tortosa (1149), carta de...

lo tanto existe un intento de crear una sociedad más permisiva en lo tocante a los comportamientos sexuales.

El artículo nueve (9) regulariza las reconciliaciones de los litigios que se puedan dar a través de los prohombres de la ciudad, antes que lleguen al tribunal. En caso de no haber conciliación de las dos partes se podrá instar demanda ante la Curia. Tanto en la Carta de Tortosa como en la Lleida la participación conciliadora de los prohombres no es de una forma legíti$\mathrm{ma}$ al que las partes pueden recurrir si lo desean. La Carta de Franquicia de Mallorca se regulariza la participación de los prohombres en las dirigencias de los litigios judiciales:

Omnia malefacta, que fuerint inter habitatores civitatis, possint probi homines pacificare et diffinere, antequam si clamor vel fundamentum ad curiam factum.

El anterior artículo enlaza con el artículo treinta y cinco (35) el cual reafirma de nuevo la conciliación de las partes ante requisito previo de la demanda, es decir que la primera providencia sea dictada por el tribunal de los prohombres. Una vez planteado el pleito el juez de los prohombres comunicará a las partes a la conciliación y de no prosperar o se requerirá a declaración, yendo a la Almudaina, sede de justicia, o se afianzará la demanda. En Carta de Franquicia de Mallorca, al igual que la de Tortosa y Lleida, existe una preocupación para una justicia eficiente, de ahí la normalización de las conciliaciones previas y de las citaciones judiciales:

De omni clamo sive dubitet sive neget reus sive confiteatur, prima a curia consilio proborum hominum sententia feratur que talis est: per totam istam diem pausate cum vestro adversario vel firmate directum vel sero ascendatis Almudaynam. Si non ad Almudaynam ascenderit, habeatur pro firmato directo, et exhibebit inde directum.

El artículo diecisiete (17) hace referencia a que ninguna autoridad real ya sea tribunal, baile o alguacil prohíbe la entrada en las propiedades privadas(casas, embarcaciones, hornos y molinos) sin acompañantes de dos 0 cuatro prohombres de la ciudad en caso tanto de sospecha como de delito. La presencia preceptiva de testigos sustituye la exigencia de mandamientos judicial. La Carta de Tortosa se contempla dicha norma al referirse a la negativa de fuerza alguna o atropello tanto de personas como de inmuebles por parte de él ni por sus súbdito, siendo las normas de justicia el marco jurídico que lo contempla. También en la Carta de Lleida se refleja dicha norma habiendo una evolución a la hora de que no se pueda increpar o inculpar sin presencia preceptiva de testigos por parte ni de guarda ni anciano: 
Curia, bajulus, sayo vel eorum locum tenens, non intrabunt domos vestras pro aliquo crimine vel causa suspitionis per se solos, sed intrabunt cum duobus vel quatuor probis hominibus civitatis. Hoc idem servabitur in navibus et lignis, furnis et molendinis.

Artículo veintiséis (26) el cual dispone que el acreedor, una vez transcurrido los diez días de vencimiento del plazo de la deuda, podrá vender la prenda durante tres días. Si la venta es superior a la deuda el acreedor abonará la diferencia al deudor y si la venta es menor al precio de la deuda el deudor tendrá que restituir la diferencia para satisfacer la totalidad. Tanto la Carta de Tortosa como de Lleida dispone que el fiador podrá vender la prenda transcurridos diez días del vencimiento de la deuda. La diferencia entre estas Cartas y la de Mallorca es la que hace referencia al caballero deudor, el cual en la normativa de Tortosa no podrá prender caballo o mulo al vencimiento del plazo teniendo que asistir a la justicia. En la Carta de Mallorca si podrá prender directamente caballo o mula, es decir, que básicamente homologa a todos los deudores:

Debitor vel fidejussor possit dare pignus suo creditori ad $X$ dies cum manulevatore idoneo, et tenebit pignus per $X$ dies, post quos vendet pignus: sed durrere illud faciet per tres dies, et si plus de suo debito inde habuerit, restitual debitori; si minus debitor vel fidejussor restituet creditori.

El artículo treinta (30) hace mención a los caballeros como posibles deudores. En caso de que caballero no saldase la deuda en su plazo el acreedor podrá prendar bienes del caballero, sin recurrir a la justicia, excepto su caballo, y en caso que no poseyera ningún otro bien se podrá tomar al caballo si no está montado en él. En la carta de Mallorca existe una clara equiparación de los deudores, ya que se homologa a los caballeros con otros deudores. La Carta de Tortosa el acreedor no puede prendar a caballero sin la autoridad judicial, y solo después del vencimiento de la deuda podrá pedir justicia para que puedan confiscarle caballos, mulas u otras cosas que poseyera:

Si miles noluerit facere justicie complementum, nec a curia posset distringi, liceat adversario suo prgnora capere propia auctoritate sua, preter equum quem ipse equitat; et si forte alia pignora non gabeat, liceat adversario milites eqqum capere, ni super eum equitet vel propria manu eum teneat.

El último artículo, veintiocho (28), tiene una clara influencia de la Carta de Población de Tortosa y de la de Lleida. Contiene una de las normas de la salvaguarda de la convivencia social. Se exime de responsabilidad penal a aquel que tomara justicia por su mano y ocasionara daño a aquel que le 
Estudio comparativo de la carta de población de Tortosa (1149), carta de...

llamara cuguç o cornudo, o renegat, renegado. Medida esta que sirve para salvaguardar la convivencia entre cristianos, judíos y sarracenos. Con clara influencia de la Carta de Tortosa que también exime de responsabilidad:

Si quis dixerit alicui cuguç vel renegat, et statim ibi dampnum aliquod accepterit, non teneatur respondere alicui domino vel ejus locum tenenti.

El escatocolo se abre con el lugar donde se expidió, el día, en calendas, mes y año:

Data apud Majoricam, kalendis Marcii, anno domini MCC tricesimo.

La validación comienza con la firma del rey y la signatura del infante Pedro con sus respectivos títulos:

Signum Jacobi Dei gratia regis Aragone et Maiorca et Valencie, comitis Barchinone et Urgelli el domini Montipessullani.

Signum Infantis Petrus illustris regis Aragone predicti filii et heredes Catalonie.

El protocolo final se cierra con la firma de los autores del documento y la data ya indicada. Hecho este que da autenticidad a la Carta:

Signum Gillelmi Scribe qui mandato domini regis pro Guillelmo de Rabacia et Guillelmo de Sala, notaris suis, hoc scribi fecit loco, die et anno prefixis.

Resaltar, tras el análisis de las tres Cartas, el carácter progresista de la Carta de Tortosa y la decisiva trascendencia de la carta en la vida de la nueva comunidad que servirá de modelo a la hora de confeccionar las posteriores cartas de población del ámbito Catalano-Balear. La estructura diplomática de la Carta de Población de Lleida, como acabamos de ver, es sustancialmente igual y en cuanto al contenido es esencialmente calcada a la Carta de Tortosa. En consecuencia tomando el patrón tortosiano solo bastaba aplicarlo a la nueva carta, modificando algunas diferencias que se pudieran dar en el nuevo territorio, ya que apenas mediaron algunos meses entre la realización de una y otra, además de ser confeccionado por el mismo escribano.

Al realizar la Carta de Franquicia de Mallorca se mejoraron las normativas más progresivas de la Carta de Tortosa además de añadir nuevos preceptos que no figuran en las anteriores cartas de población. Al valorar globalmente la Carta de Franquicia de Mallorca, tanto los que la elaboraron como los que la desarrollaron testimoniaron un sentido de anticipación y visión de futuro. 